\title{
On the Rigid-Ideally Plastic Deformation of Cantilever Bean Subjected to Tip Impact
}

\author{
Ming-Te Liang \\ Associate Professor, Department of Harbor and River Engineering National Taiwan Ocean University Keelung, Taiwan, \\ R.O.C. \\ Bon-Jofei Lee \\ Graduate Student, Department of Harbor and River Engineering National Taiwan Ocean University Keelung, Taiwan, \\ R.O.C. \\ Sen-Shyang Yang \\ Graduate Student, Department of Harbor and River Engineering National Taiwan Ocean University Keelung, Taiwan, \\ R.O.C.
}

\section{Recommended Citation}

Liang, Ming-Te; Lee, Bon-Jofei; and Yang, Sen-Shyang (1997) "On the Rigid-Ideally Plastic Deformation of Cantilever Bean Subjected to Tip Impact," Journal of Marine Science and Technology. Vol. 5: Iss. 1, Article 5. DOI: 10.51400/2709-6998.2536

Available at: https://jmstt.ntou.edu.tw/journal/vol5/iss1/5

This Research Article is brought to you for free and open access by Journal of Marine Science and Technology. It has been accepted for inclusion in Journal of Marine Science and Technology by an authorized editor of Journal of Marine Science and Technology. 


\title{
ON THE RIGID-IDEALLY PLASTIC DEFORMATION OF CANTILEVER BEAM SUBJECTED TO TIP IMPACT
}

\author{
Ming-Te Liang*, Bon-Jofei Lee** and Sen-Shyang Yang**
}

Keywords: Rigid-plastic, Elastic-plastic, Plastic Hinge.

\section{ABSTRACT}

This paper presents to study the resemblance and discrepancy between the rigid-plastic and elastic-plastic deformation of cantilever beams subjected to tip impact. For this, the theory of Ting's analysis [3] and calculation parameter obtained from Parkes [1] and Symonds and Fleming [4] are used for numerical computation. These results obtained from rigid-plastic deformation are compared with those results calculated by Reid and Gui [8] who used the non-linear finite-element code ABAQUS for presenting the numerical solution of the elastic-plastic deformation of cantilever beams. No matter what rigid-plastic or elastic-plastic deformation, the kink phenomena of the plastic hinge arrest mechanism is all happen. The more the ratio of kinetic energy to fully plastic moment, the more kink phenomena. However, in the case of relationship between distance from root of cantilever and time, the position and time of plastic hinge happen in rigid-plastic deformation is difficult to predict while is easy for elastic-plastic deformation.

\section{INTRODUCTION}

A classical problem of rigid-plastic structural dynamics was solved by Parkes [1]. This problem is to find the deformations of a cantilever beam carrying a mass at its tip which is subjected to a short pulse loading. The rigid-plastic theorem for a considerable body has been developed based on the neglect of elastic strain component, the idealization of perfectly plastic behavior (absence of strain hardening or strain rate sensitivity), and the assumption of linear field equations ignoring effects of geometry changes. In the Parkes problem, the axial elongation is ne-

Paper Received January, 1997. Revised April, 1997. Accepted April, 1997. Author for Correspondence: Ming-Te Liang.

*Associate Professor, Department of Harbor and River Engineering National Taiwan Ocean University Keelung, Taiwan, R.O.C.

**Graduate Student, Department of Harbor and River Engineering National Taiwan Ocean University Keelung, Taiwan, R.O.C. glected. Bodner and Symonds [2] used a different approach which is considered a strain rate dependent yield stress into the governing equations to study the Parkes problem.

Parkes considered a cantilever beam of uniform cross section with a mass $\boldsymbol{G}$ attached at its end subjected to a transverse impact velocity $V_{o}$ at the tip mass (see Fig.1. (a)). The length and mass of the beam is respectively $L$ and $m L$. The maximum elastic energy of bending which can be absorbed in the beam is $M_{o}^{2} L / 2 E I$ in which $E$ is the Young's modulus, $M o$ is the yield moment of the beam, and $I$ is the moment of inertia of the cross section. One considers a class of impacts in which the input kinetic energy $G V_{o}^{2} / 2$ is much larger than the maximum elastic energy which the beam can absorb. In the other words, the energy ratio,

$$
R=\frac{1}{2} G V_{o}^{2} \frac{2 E I}{M_{o}^{2} L},
$$

is assumed to be much larger than one. Therefore, the material can be regarded as rigid, ideally plastic such that no deformation occurs when the bending moment at a cross section is smaller than the yield moment $M_{0}$ and indefinite deformation can occur when it exceeds $M_{0}$.

Ting[3] has formulated the rigid-ideally plastic large deformation analysis and has shown that one must employ numerical techniques to solve the equations. Symonds and Fleming [4] revisited the Parkes problem and analyzed the behavior of a steel beam shown schematically in Fig.1(a) of length $\boldsymbol{L}=356 \mathrm{~mm}$, width $\boldsymbol{b}=16.3 \mathrm{~mm}$, and depth $h=4.5 \mathrm{~mm}$ carrying a tip mass $G=0.336 \mathrm{Kg}$ under a variety of impulsive loads. These dimensions correspond to test $\mathrm{E} 4$ reported in [2]. The test conditions were defined in terms of the energy ratio $\mathrm{R}$ given by Eq.(1). Values of $R$ ranging from 2 to 14.8 were considered, these corresponding to values of $V_{o}$ ranging from 4.7 to $12.9 \mathrm{~ms}^{-1}$. Symonds and Fleming produced exact 
elastic, ideally plastic solutions using the finite-element Code ABAQUS [5]. In these, the material was assumed to be strain-rate independent and the result could be compared directly with the Parkes analysis and the results of the simplified elastic-plastic (SEP) method $[6,7]$.

In[4] bending moment distribution at various times were expressed for the case $R=2$. It was denoted that those corresponding to early times provided little resemblance to the bending moment distribution corresponding to the traveling plastic hinge phase of the Parkes solution as shown in Fig. 1(b). In fact these moment distributions nowhere gotten the magnitude of the fully plastic moment $M_{o}$ within the span of the beam. At later times the exact solution did indicate an obvious modal type of moment distribution with a plastic hinge at the root of the cantilever as assumed in the second phase of the SEP method. In addition the distribution of plastic work throughout the beams for $R=2 \sim 14.8$ at various times shown significant difference from the predictions of the Parkes solution which are shown in Fig. 1(c) and (d). This result in the additional discrepancy that the plastic work dissipated in the interior of the beam in the exact solution is significantly less than that predicted by the rigid-plastic theory. This discrepancy increased as $R$ increased over the range revealed in [4].

Reid and Gui[8] used ABAQUS programme to

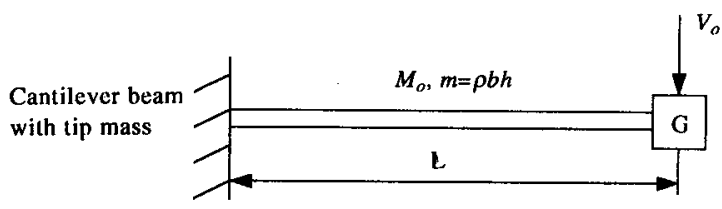

(a)Geometry and initial condition

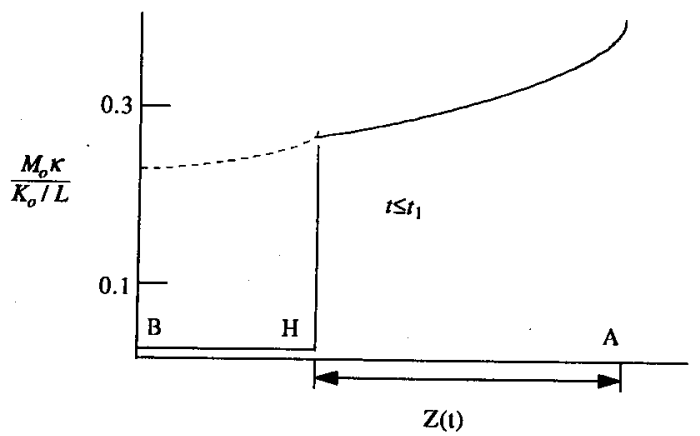

(c)plastic work distribution during travelling hinge phase identify the major role played by elastic deformation in affecting the distribution of plastic deformation in an impulsively loaded cantilever beam carrying a tip mass. The finite element calculations have shown that for an elstic-perfectly plastic cantilever initially a region of maximum bending moment (plastic hinge) propagates from the tip in a manner which is well described by the model formulated by Parkes. However, the effect of the reflection of the proceeding elastic bending wave train is to arrest the progress of this region causing the hinge to oscillate for a short time about the center of the beam. The arrest of the traveling hinge is triggered by the formation of a reversed (negative) hinge at the root of the cantilever and means that the root rotation phase can be delayed. In addition, the occurrence of the kink often evident in beams and bars subjected to tip impact is well explained by the hinge arrest mechanism. When strain-rate effects are considered, it would appear that the elastic waves play essentially the same role as in the elastic-plastic case. The viscoplastic effects redistribute the deformation somewhat and in particular create a more diffuse plastic zone near the root of the cantilever and reduce the severity of the kink with the beam.

In this paper, one takes into account the geometrical effects on large deformation of a rigidly, ideally plastic cantilever beam suggested by Ting [3]. The main purpose of this work uses the Ting theory

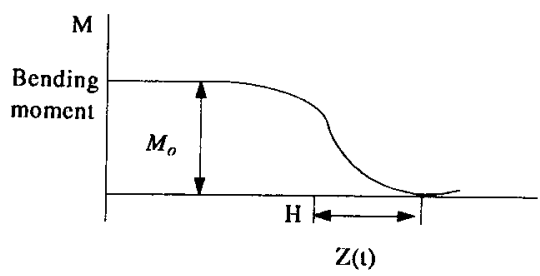

(b)Bending moment distribution during travelling hinge phase

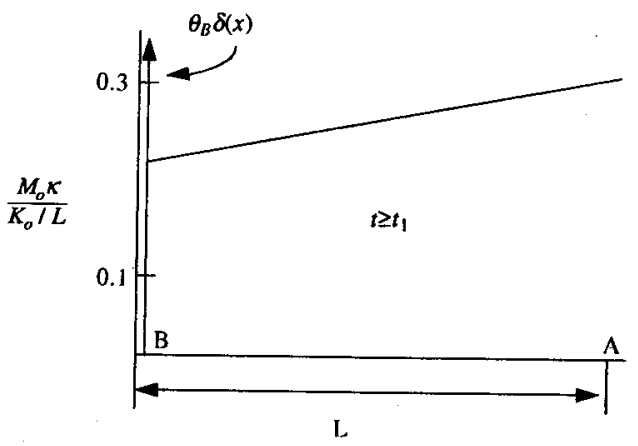

(d)plastic work distribution during root rotation phase.

Fig. 1. Parks' cantilever ploblem. 
[3] to reexamine the discrepancies between the Symonds-Fleming [4] and Parkes [1] solution in order to compare the results obtained by the ABAQUS programme [8].

\section{THEORERETICAL REVIEW}

\section{Ting's Analysis}

Figure 2(a) shows a typical state of deformation at any time $t$ in which a plastic hinge appears at a distance $\zeta l$ from the tip, where $\zeta$ is the position of the plastic hinge and is the function of time $t, l$ is an arbitrary length which can be chosen equal to $L$. In Ting's analysis[3], one will choose $l=G / m$, and the length of the beam in nondimensional notation is $s=L / l=m L / G$ (Fig. 2(b)). For convenience, the following nondimensional quantities will be used in the analysis:

$$
s=\frac{m L}{G}, t=\frac{m M_{o} T}{G^{2} V_{o}}, \alpha=\frac{G V_{o}^{2}}{2 M_{o}} .
$$

If $\zeta$ is a one-to-one function of $\mathrm{t}$, one can take $\zeta$ as an independent variable instead of $t$. Hence, the slope angle $\theta(x, \zeta)$ at $\mathrm{x}$ (see Fig. 2(b)) when the plastic hinge at $\zeta$ is

$$
\theta(x, \zeta)=\int_{x}^{\zeta} k(\xi) d \xi
$$

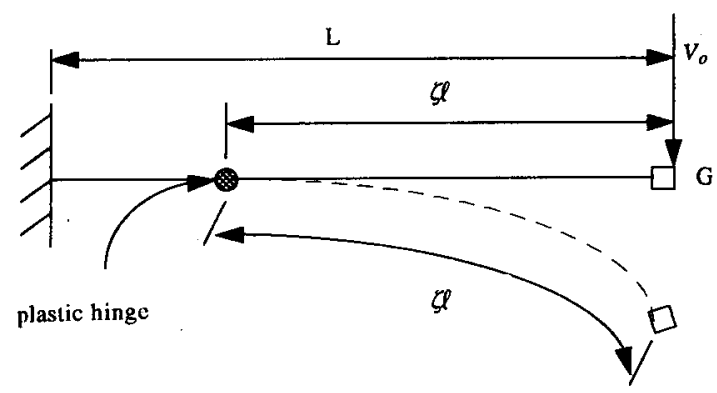

(a)Deformation during travelling plastic hinge

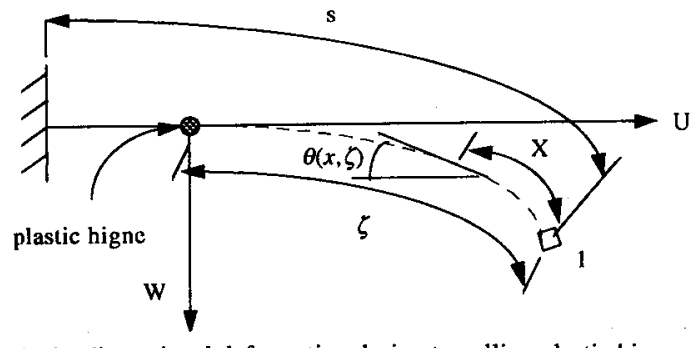

(b)Nondimensional deformation during travelling plastic hinge

Fig. 2. Ting's analysis for the Parkes Cantilever beam. where $K(x)$ is the nondimensional curvature of the cantilever beam at $x$. Based on rigid ideally plastic theory, the deformation in the cantilever beam at any instant occurs merely at the plastic hinge. Therefore

$$
\begin{aligned}
& K(x)=0 \quad x>\zeta, \\
& k(x)=\text { constant. }
\end{aligned}
$$

If one defines

$$
\begin{aligned}
& U(x, \zeta)=\int_{x}^{\zeta} \cos \theta(\xi, \zeta) d \xi, \\
& W(x, \zeta)=\int_{x}^{\zeta} \sin \theta(\xi, \zeta) d \xi .
\end{aligned}
$$

Then, the first moment of the deformed portion of the beam about the $\mathrm{W}, \mathrm{U}$ - axes and the second moment about plastic hinge are, respectively (Fig. 2(b)),

$$
\begin{aligned}
I_{1}(\varsigma) & =\int_{0}^{\varsigma} U(x, \varsigma) d x+U(0, \varsigma), \\
I_{2}(\varsigma) & =\int_{0}^{\zeta} W(x, \zeta) d x+W(0, \varsigma), \\
I_{0}(\varsigma) & =\int_{0}^{\zeta}\left[U^{2}(x, \zeta)+W^{2}(x, \zeta)\right] d x \\
& +\left[U^{2}(0, \varsigma)+W^{2}(0, \varsigma)\right] .
\end{aligned}
$$

The equations of conservation of linear and angular momentum are, respectively,

$$
\begin{aligned}
& 2 \alpha=\left\{\frac{d \zeta}{d t} K(\zeta)\right\} I_{1}(\zeta), \\
& t=\zeta-\frac{1}{2 \alpha}\left\{\frac{d}{d t} K(\zeta)\right\} I_{o}(\zeta),
\end{aligned}
$$

where the term in square brackets is essentially the angular velocity of the deformed portion of the cantilever beam about the plastic hinge. The energy equation furnishes

$$
\int_{0}^{\zeta} K(x) d x+\frac{1}{4 \alpha}\left\{\frac{d \zeta}{d t} K(\zeta)\right\}^{2} I_{o}(\zeta)=\alpha .
$$

Substituted Eq.(7a) to Eq.(8), one obtains

$$
\int_{0}^{\zeta} K(x) d x+\alpha \frac{I_{0}(\zeta)}{I_{1}^{2}(\zeta)}=\alpha .
$$

Directly differentiating Eq. (6) with the aid of Eqs. (3) and (5), one gets

$$
\begin{aligned}
& \frac{d}{d \zeta} I_{1}(\zeta)=1+\zeta-K(\zeta) I_{2}(\zeta), \\
& \frac{d}{d \zeta} I_{2}(\zeta)=K(\zeta) I_{1}(\zeta), \\
& \frac{d}{d \zeta} I_{0}(\zeta)=2 I_{1}(\zeta)
\end{aligned}
$$

Equation (9), with the aid of Eq.(10), is reduced to be 


$$
K(\zeta)=2 \alpha \frac{(1+\zeta) I_{0}(\zeta)-I_{1}^{2}(\zeta)}{I_{1}^{3}(\zeta)+2 \alpha I_{0}(\zeta) I_{2}(\zeta)}
$$

Therefore, the set of Eqs. (3), (5), (6) and (11) furnish the solution for $K(\zeta)$ and also for $I_{1}(\zeta), I_{2}(\zeta)$, and $I_{0}(\zeta)$. The motion of the cantilever beam is a rigidbody rotation about the root when the plastic hinge gets to the root $\zeta=s$. Let $\theta_{s}$ presents the angle due to this rotation. After that the input kinetic energy $\alpha$ amounts to the energy absorbed in the plastic deformation of the cantilever beam when the deformation is finished, one has

$$
\int_{0}^{s} K(x) d x+\theta_{s}=\alpha
$$

Substituting Eq. (3) into Eq. (12a), one yields

$$
\theta(0, s)+\theta_{s}=\alpha
$$

Comparing Eq.(12b) to Eq.(9), one gets

$$
\theta_{s}=\alpha \frac{I_{0}(s)}{I_{1}^{2}(s)}
$$

When the plastic hinge reaches the root $\zeta=s$, the right-hand side of Eq. (13) is equivalent to the kinetic energy of the cantilever beam. Because $I_{0}(s)$ never grows to be zero for $s \neq 0$, the kinetic energy of the cantilever beam never vanishes before the plastic hinge gets to the root. The final deformation $\theta_{f}(x)$ of cantilever beam with Eq. (12b) is

$$
\begin{aligned}
\theta_{f}(x) & =\theta_{s}+\theta(x, s) \\
& =\theta_{s}+\theta(0, s)-\theta(0, x) \\
& =\alpha-\theta(0, x) .
\end{aligned}
$$

Comparing Eq. (9) with Eq. (14a) with the aid of Eq. (13), one obtains

$$
\theta_{f}(x)=\left.\theta_{s}\right|_{-s=x}=\alpha \frac{I_{0}(s)}{I_{1}^{2}(s)} .
$$

Equation (14b) means that the final slope angle at any point $x$ is equal to the nondimensional kinetic energy in the cantilever beam when the plastic hinge reaches the section at $x$. This result is derived from consideration only of work and energy. The final slope angle $\theta_{f}(0)$ at the tip and is

$$
\theta_{f}(x)=\alpha=\frac{G V_{0}^{2}}{2 M_{o}} .
$$

$\theta_{f}(x)$ and $\theta_{f}(0)$ are independent of the length $s$ of the cantilever beam. In other words, for a given tip mass and a cantilever beam cross section, the final slope angle at any cross section is independent of the total length of the beam.
In order to find the time $t$ as a function of $\zeta$, one eliminates the term in square brackets in Eq. (7b) from Eq. (7a), and has

$$
t(\zeta)=\zeta-\frac{I_{0}(\zeta)}{I_{1}(\zeta)}
$$

Equation (16) with the aid of Eq. (7b), the time $t_{s}$ required in the rigid-body rotation of the cantilever beam about the root after the plastic hinge reaches the root is

$$
t_{s}=\left.\frac{I_{0}(s)}{2 \alpha}\left\{\frac{d \zeta}{d t} K(\zeta)\right\}\right|_{-\zeta=s}=\frac{I_{0}(s)}{I_{1}(s)} .
$$

The total time $t_{f}$ for the complete deformation is

$$
t_{f}=t_{s}+t(s)=s
$$

It is worthy to point out that the quantities $K(s), \theta_{f}(x)$, $\theta_{s}, t_{s}$, and $\mathrm{t}$ are all expressed in terms of $I_{1}, I_{2}$, and $I_{0}$.

\section{PARKES' SOLUTION}

In Parkes' solution, the displacements are assumed to be small. Then Eq. (6) becomes

$$
\begin{aligned}
& I_{1}(\zeta) \cong \int_{0}^{\zeta} x d x+\zeta=\frac{\zeta^{2}}{2}+\zeta, \\
& I_{2}(\zeta) \cong 0, \\
& I_{0}(\zeta) \cong \int_{0}^{\zeta} x^{2} d x+\zeta^{2}=\frac{\zeta^{3}}{3}+\zeta .
\end{aligned}
$$

Substituting Eq. (19) into Eq. (11), after replacing $\zeta$ by $\mathrm{x}$, provides

$$
K(x)=\frac{4 \alpha}{3} \frac{x+4}{(x+2)^{3}} .
$$

Notice that Parkes' assumption is equivalent to assuming

$$
K(x) \cong-\frac{d^{2} y_{f}}{d x^{2}},
$$

and

$$
\theta_{f}(x) \cong-\frac{d y_{f}}{d x}
$$

where $y_{f}(x)$ is the final vertical displacement of section $x$. Thus, Eqs. (13) and (14b) become, respectively,

$$
\theta_{s} \cong-\left.\frac{d y_{f}}{d x}\right|_{-x=s}=\frac{4 \alpha}{3} \frac{s+3}{(s+2)^{2}},
$$

and

$$
\theta_{f}(x) \cong-\frac{d y}{d x}=\frac{4 \alpha}{3} \frac{x+3}{(x+2)^{2}} ;
$$


and the solution for $y_{f}$ is

$$
y_{f}(x)=\frac{4 \alpha}{3}\left[\log \left(\frac{s+2}{x+2}\right)+\frac{s-x}{(x+2)(s+2)}\right] .
$$

Equation (16) gives

$$
t=\frac{\zeta^{3}}{3(\zeta+2)} \text {. }
$$

It should be noticed that these agree with results obtained by Parkes [1].

\section{RESULTS AND DISCUSSION}

All the numerical solutions presented were derived using the Ting analysis [3] and Parkes solution[3]. The formulation of the problem was essentially the same as that used in [4]. The parameters used in the calculation for the two strain-rate independent examples are given in Table 1.

\section{Example 1: Case $R=14.8$ from [4]}

The parameters defining this problem are given in Table 1. Since $\theta_{f}(0)=\alpha=G V_{0}^{2} / 2 M$, it is of particular interest when $\alpha$ exceeds $\pi / 2$. For a cantilever beam with rectangular cross section of width $b$ and height $\mathrm{h}$, the relationship between $\alpha$ and $\mathrm{R}$ is

$$
R=\left(\frac{G V_{0}^{2}}{2 M_{0}}\right) \frac{2 E I}{M_{0} L}=\alpha \frac{2 E}{3 \sigma_{0}} \frac{h}{L},
$$

where $\sigma_{o}=M_{o} h / 3 I$ is the yield stress. If one takes $2 E / \sigma_{o} \cong 500$ (which is the case for most steels and aluminum alloys) one has

$$
\alpha \cong \frac{R}{500} \frac{L}{h} .
$$

\begin{tabular}{|c|c|c|}
\hline Parameters & $\begin{array}{c}\text { Example } 1 \\
\text { Symonds and Fleming } \\
\mathbf{R}=14.8\end{array}$ & $\begin{array}{c}\text { Example } 2 \\
\text { Parkes } \\
\beta=21.96 \\
\end{array}$ \\
\hline $\mathrm{E}\left(\mathrm{Nmm}^{-2}\right)$ & $2.069 \times 10^{5}$ & $2.069 \times 10^{5}$ \\
\hline$\sigma_{o}\left(\mathrm{Nmm}^{-2}\right)$ & 200 & 344 \\
\hline$M_{o}(\mathrm{Nm})$ & 16.5 & 24.8 \\
\hline$\rho\left(\mathrm{kgm}^{-3}\right)$ & 7850 & 7493 \\
\hline$L(\mathrm{~mm})$ & 355.6 & 304.8 \\
\hline$b(\mathrm{~mm})$ & 16.3 & 6.6 \\
\hline$h(\mathrm{~mm})$ & 4.5 & 6.6 \\
\hline$G(\mathrm{~kg})$ & 0.336 & 0.0023 \\
\hline$V_{o}\left(\mathrm{~ms}^{-1}\right)$ & 12.9 & 251.5 \\
\hline$\beta=\rho L b h / 2 G$ & 0.305 & 21.96 \\
\hline$K_{o}(J)$ & 27.9 & 137.4 \\
\hline$R=2 K_{o} E I / M_{o}^{2} L \mathrm{M}$ & 14.8 & 51.7 \\
\hline No. of elements & 28 & 24 \\
\hline
\end{tabular}

Table 1. Computation parameters for $10<\mathrm{R}<20$ and $10<\mathrm{L} / \mathrm{h}<100,0.2<\mathrm{a}<4$. With this range of $\alpha, \theta_{f}(0)$ can exceed p. Using Eq. (14b) and the principle of superpositions, one gets the relationship between deformation and distance from root as shown in Fig. 3 shows four sketches for the deformations of the cantilever beam with $a=p / 2$, $a=p, a=2 p, a=3 p$, respectively. Fig. 3 indicates that the distribution of plastic work corresponding to the Ting analysis against reflects the effect of the arrest of the traveling hinge around the center of the cantilever and this is further evidenced by the localized kink in the final slope of the deformed cantilever beam. Hall et al. [9] have evidenced the qualitative characteristics of kink for an aluminum cantilever beam follow impact at tip by a bullet. The bending moment distribution can be obtained the same method as Fig. 3. Fig. 4 shows that the existence of a maximum bending moment of $M_{o}$ at the tail of the distributed region. The main feature of this phenomena is that the position of plastic hinge moves along the cantilever beam as this progresses. Hence, the various positions of the plastic hinge provides in Fig. 5 which is obtained from Eq. (17). Fig. 5 means

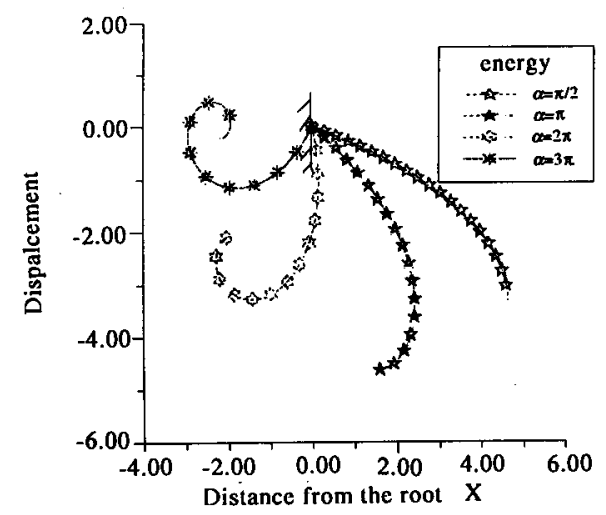

Fig. 3. Final shape of deformed Cantilever, distribution for Example 1 deformation complete.

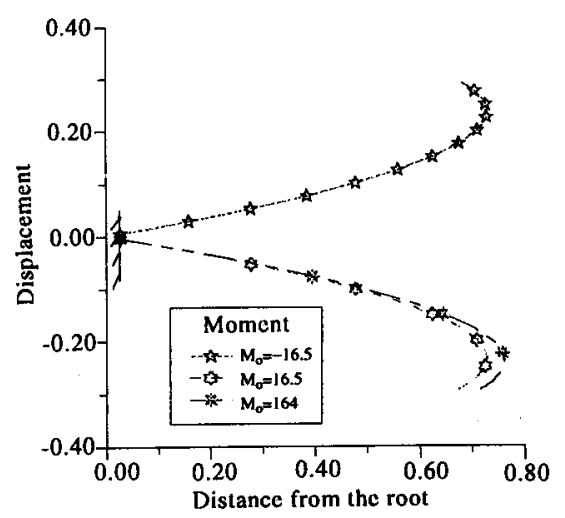

Fig. 4. Bending moment Example 1, after all plastic. 
that the rigid-plastic moment distribution full plasticity is only achieved over small regions of the cantilever beam except for the very short time which precedes the formation of the final, positive root hinge.

\section{Example 2: Parkes bullet impact}

As an example of high-velocity, low projectile mass impact consider test $C \geq 4$ described in [1]. The calculation parameters defining this problem are given in Table 1 [8].

Let $\alpha=3 \mathrm{p}$ in Eq.(23b), one gets the relationship between deformation and distance from the root as shown in Fig. 6. The kink phenomena can not be shown in Fig. 6. This is quite different from the deformation of an elastic- plastic cantilever beam as shown in Fig. 9 in Ref [8]. In order to evidence the maximum bending moment of $M_{o}$ at the tail of the disturbed region, one uses $a=3 p$ in Eqs. (17b) and

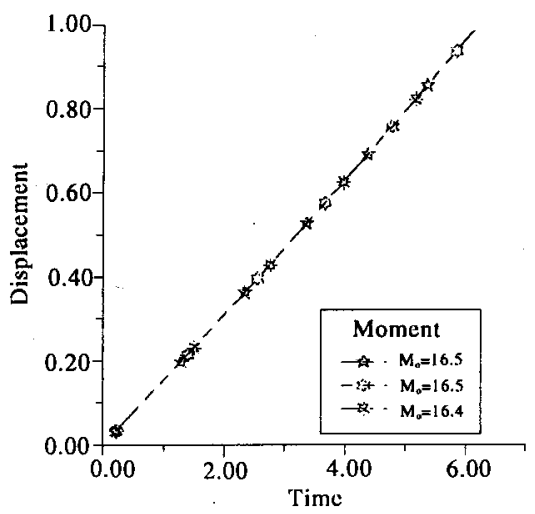

Fig. 5. Position and extent of plastic region $\left(M=M_{o}\right)$ for Example 1 ploted as a function of time.

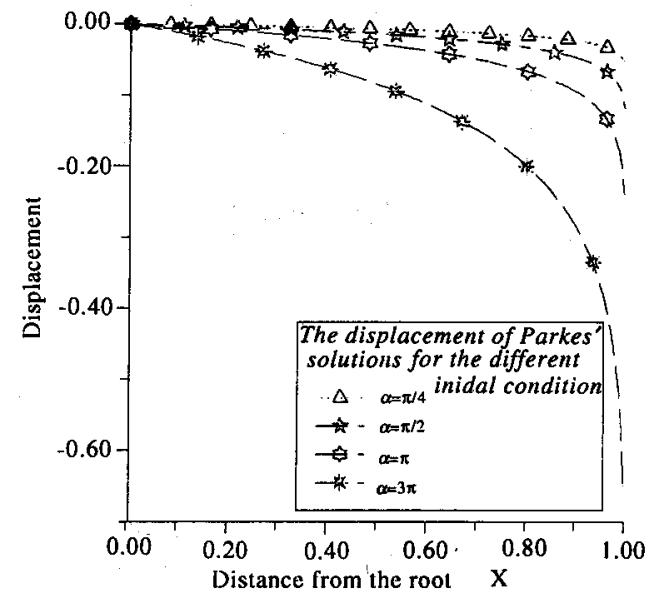

Fig. 6. Final shape of deformed cantilever, Example 2, after all plastic deformation complete. (23b) to get the result as shown in Fig. 7. It should be noticed that the results of Ting's analysis is of difference with Parkes' solution which is neglected the axial elongation. The position of the plastic hinge given by the Parkes theory is

$$
t=\frac{m V_{o}}{6 M_{o}} \frac{Z^{2}}{\left(1+\frac{\beta Z}{L}\right)},
$$

where $m=\rho b h$ is the mass per unit length of the beam and $Z(x)$ is the distance of plastic hinge from the tip. Using Eq. (25) or(28), the progress of the plastic hinge is shown in Fig. 8. If Fig. 8 is compared with Fig. 7 in Ref[8], then one knows that the Parkes analysis shows good agreement with the elastic-plastic solution until the arrest of the plastic hinge following the formation of the reversed hinge at the root. Hence, the degree of agreement between the kinematics of the internal hinge, as provided by the rigidplastic solution and the elastic-plastic solution is quit striking, the major difference being the dwell in the

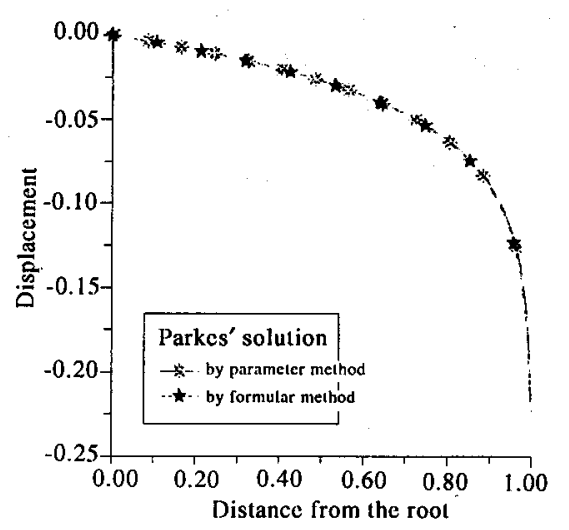

Fig. 7. Bending moment distribution for Example 2.

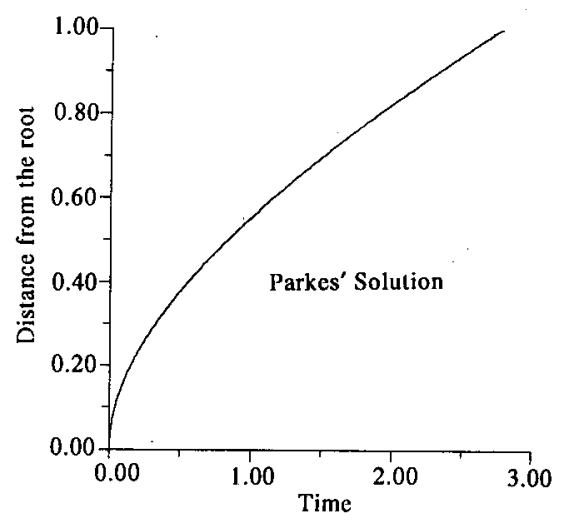

Fig. 8. Position of plastic hinge for Example 2 (Parkes' solution) as a function of time. 
progress of the traveling plastic hinge which leads to the root rotation just the different time pointed by Reid and Gui [8].

\section{Example 3: Influence of strain-rate sensitivity in Example 2.}

For the sake of illustrating the effect of strainrate sensitivity in this problem, Example 2 was resolved using Ting's analysis. The power-law relationship employed in this analysis in taken to have the form:

$$
\sigma=\sigma_{0}\left[1+\left(\frac{\dot{\varepsilon}}{D}\right)^{\frac{1}{p}}\right]
$$

in which is the static yield stress is yield stress (in general a function of strain rate) $\dot{\varepsilon}$ is strain rate, D is constant and $p$ is exponent. This was achieved by using Eq. (29) in the material considered representative for steel. The main features of the numerical results are shown in Fig. 9. Fig. 9 displays that the distribution of plastic work has been modified by the influence of strain-rate effects. This implies that the curvature changes in the tip region for the strainrate independent case are considerably less in the strain-rate dependent case.

\section{CONCLUSIONS}

The numerical calculations mentioned above are focused on identifying the major role played by large deformation in affecting the distribution of rigid-plastic deformation in an impulsively loaded cantilever beam carrying a tip mass.

The numerical calculations have shown that for a rigid-ideally plastic cantilever beam initially a region of maximum bending moment (plastic hinge) propagates from the tip in a way which is well

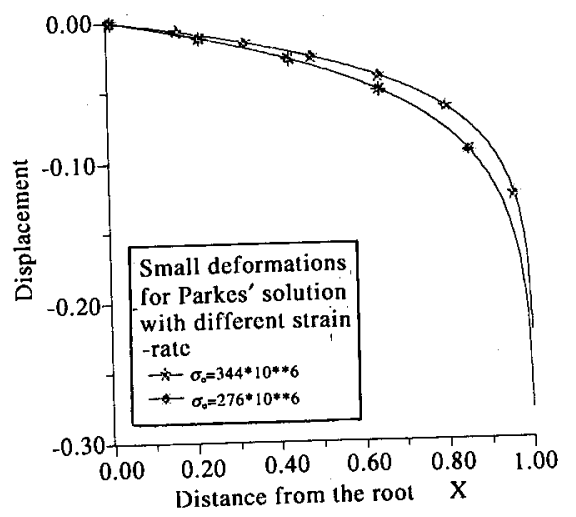

Fig.9. Deformation for parkes' solution compared using modification with before modifing. evidenced by the model formulated by Parkes [1]. However, the results obtained from a rigid-ideally plastic cantilever beam have some resemblance and different from those obtained from an elasticperfectly plastic cantilever. No matter what rigidplastic or elastic-plastic deformation, the kink phenomena of the plastic hinge arrest mechanism is all happen. The more the ratio of kinetic energy to fully plastic moment, the more kink phenomena. However, in the case of relationship between distance from root of cantilever and time, the position and time of plastic hinge happen in rigid-plastic deformation is difficult to predict whereas is easy for elastic-plastic deformation.

\section{REFERENCES}

1. Parkes, E.W., "The Permanent Deformation of a Cantilever Struck Transversely at Its Tip," Proceedings of Royal Society, London, series A, Vol. 228, pp. 462476 (1995).

2. Bodner, S.R. and Symond, P-S., "Experimental and Theoretical Investigation of the Plastic Deformation of Cantilever Beams Subjected to Impulsive Loading," Journal of Applied Mechanics, Transactions of the ASME, December, pp. 719-728 (1962).

3. Ting, T.C.T., "Large Deformation of a Rigid, Ideally Plastic Cantilever Beam," Journal of Applied Mechanics, Transactions of the ASME, June, pp. 295-302 (1965).

4. Symonds, P-S. and Fleming, W.T.Jr., "Parkes Revisited: On Rigid-Plastic and Elastic-Plastic Dynamic Structural Analysis," International Journal of Impact Engineering, Vol. 2, No. 1, pp. 1-36 (1984).

5. Hibbitt, H.D., "ABAQUS-EPGEN-a General Purpose Finite-Element Code with Emphasis on Non-linear Application," Nuclear Engineering and Design, Vol. 77, pp. 271-297 (1984).

6. Symonds, P-S., "Elastic-Plastic Deflections Due to Pulse Loading, Dynamic Response of Structures" Proceedings of Specialty Conference held in Atlanta, GA. 15-16 January (Edited by Gary Hart), ASCE, New York, pp. 887-901 (1981).

7. Symonds, P-S. and Mosquera, J.M., "A Simplified Approach to Elastic-Plastic Response to General Pulse Loads," Journal of Applied Mechanics, Vol. 52, Transactions of the ASME, pp. 115-121 (1985).

8. Reid, S.R. and Gui, X.G.,"On the Elastic-Plastic Deformation of Cantilever Beams Subjected to Tip Impact," International Journal of Impact Engineering, Vol. 6, No. 2, pp. 109-127 (1987).

9. Hall, R.G., Al-Hassani, S.T.S. and Johnson, W., "The Impulsive Loading of Cantilever," International Journal of Mechanical Science, Vol. 13, pp. 415-430 (1971). 


\section{論懸臂樑末端承受衝擊作用引致剛}

\section{塑性變形}

梁明德李鹏飛楊森翔

國立台管海洋大學河海工程研究所

摘 要

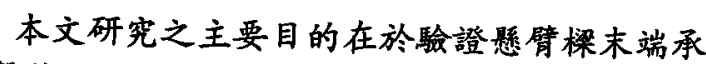
受街慗作用, 引致㣚塑性、彈塑性警形之相似性及 差異性, 為此, 引用Ting (1965)之䚋念及Parkes (1955), 和Symonds and Fleming (1985)的变驗参 数作数值补算, 此㣚塑性讐形結果與Reid and Guid (1987)採用有限元素法的ABAQUS軟體数值补算的 結果比較之, 由此得知不端㣚塑性或彈塑性娤形, 扭結現象均會發生。當動能與完全塑性力矩的比值 越大時, 扭結現象愈影著, 而且若再考虑應枚效應

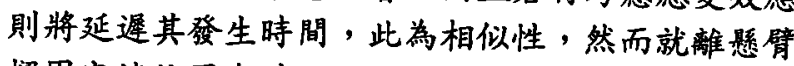
樑固定端位置與時間的開係而言, 㣚塑性玟形不若 彈塑性曒形那般容易得知塑性鉸發生的位置與時 間, 此為差具性。 